Supporting information for:

\title{
Solution-Chemical Synthesis of Carbon Nanotube/ZnS Nanoparticle Core/Shell Heterostructures
}

\author{
Feng $\mathrm{Gu}$, ${ }^{*}$ Chunzhong $\mathrm{Li}$, * Shufen Wang
}

Key Laboratory for Ultrafine Materials of Ministry of Education, School of Materials Science and Engineering, East China University of Science \& Technology,

Shanghai 200237, China

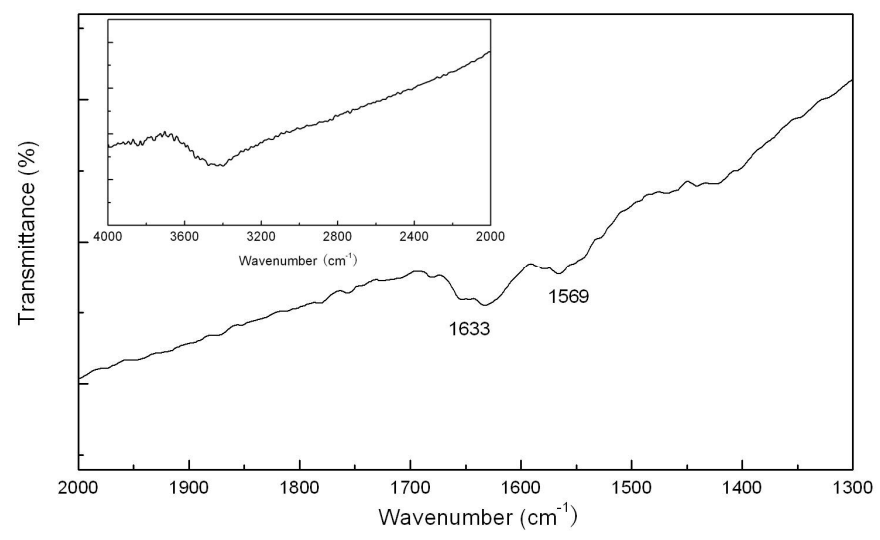

Figure S1. FTIR spectrum of the formed MWCNT/ZnS heterostructures.

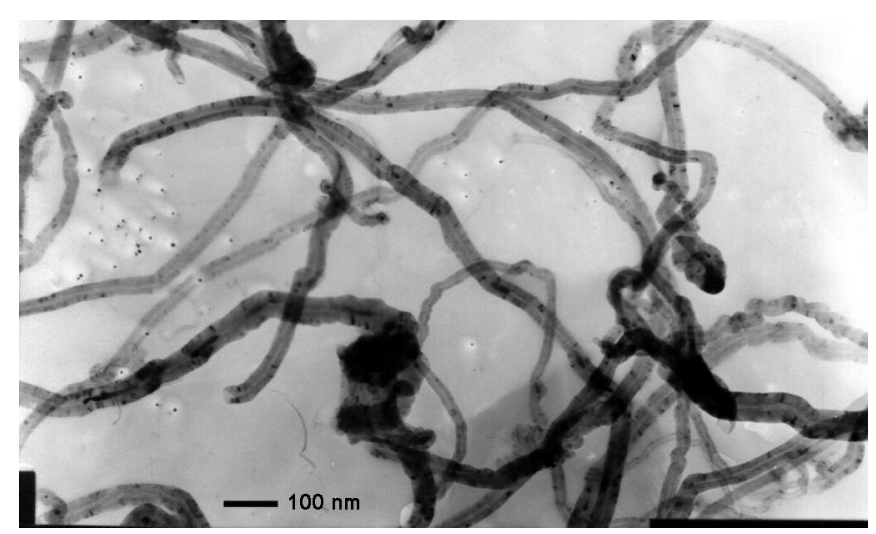

Figure S2. TEM image of the MWCNTs. 


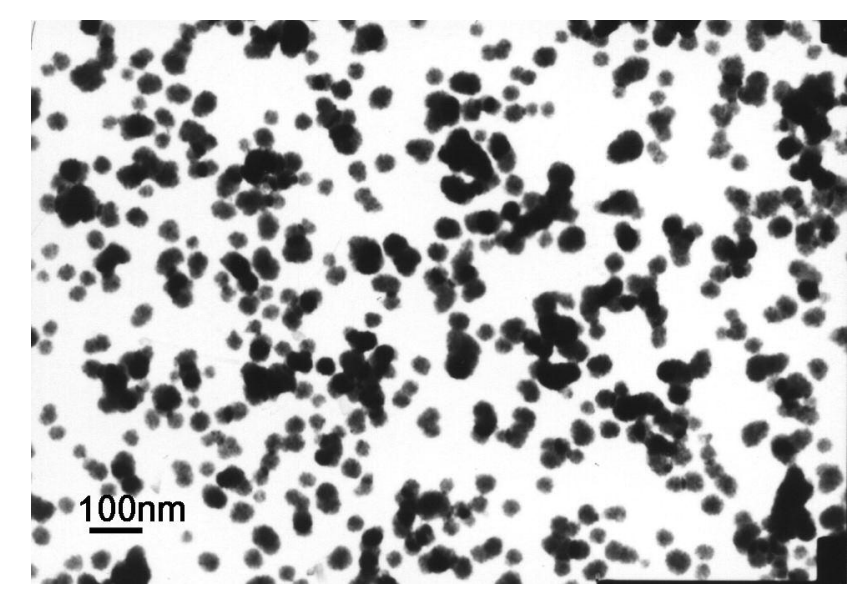

Figure S3. TEM image of the formed ZnS nanoparticles when no MWCNTs were used.

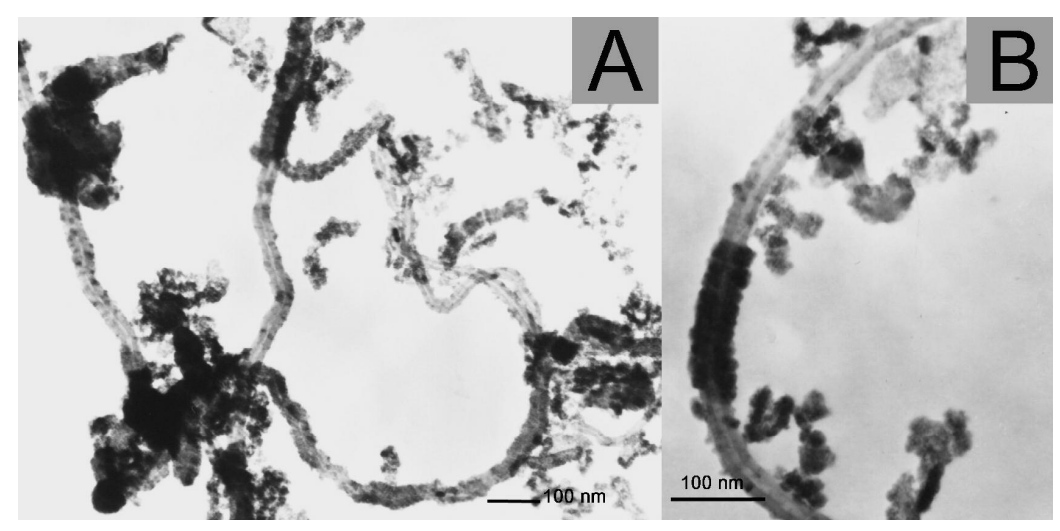

Figure S4. TEM image of the MWCNT/ZnS sample prepared without the aid of sonication process and the other experimental condtions were analogous.
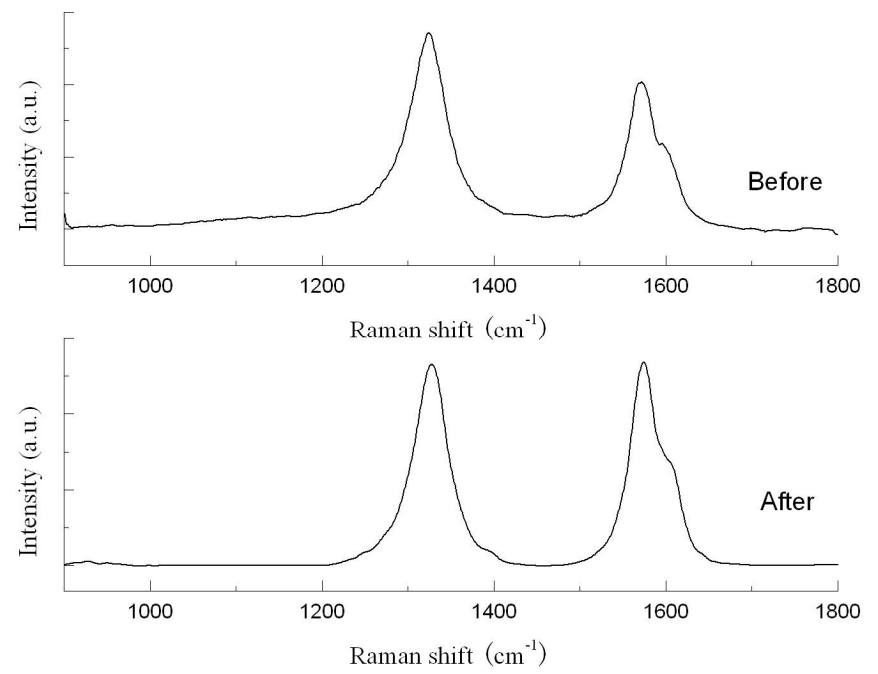

Figure S5. Raman spectra of the MWCNT samples before and after sonication. 


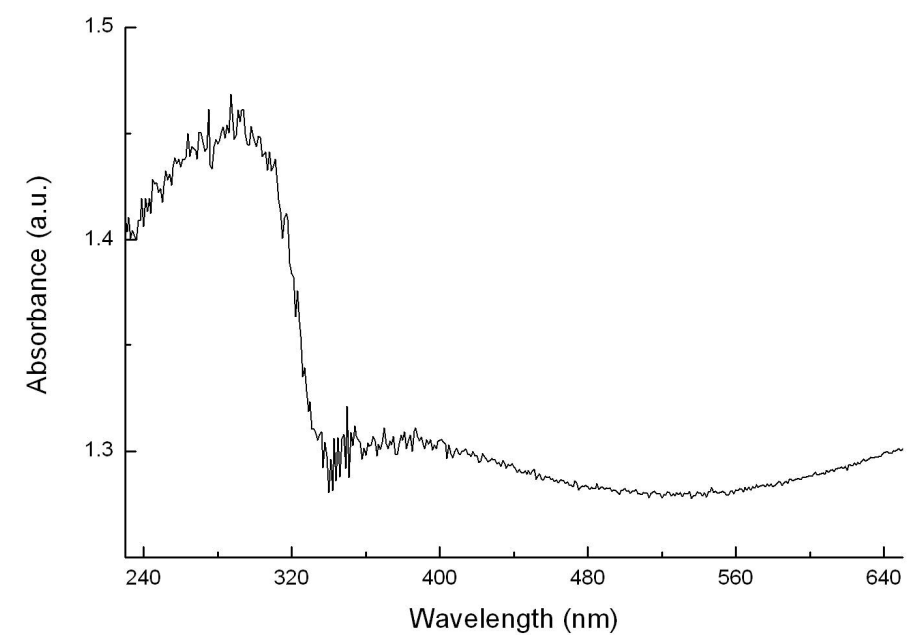

Figure S6. UV-vis absorption spectrum of MWCNT/ZnS heterostructures.
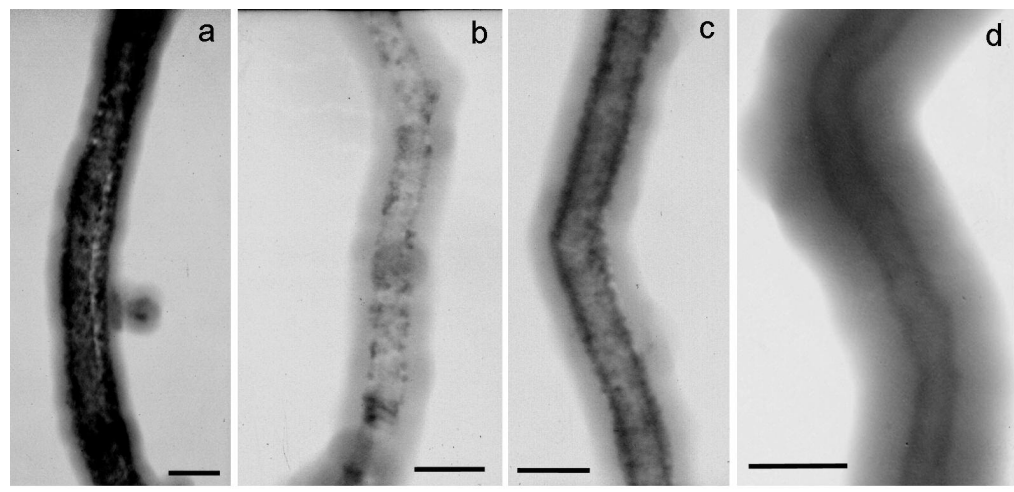

Figure S7. TEM images of the formed MWCNT/ZnS/SiO ${ }_{2}$ heterostructures with different silica thickness: (a) $20 \mathrm{~nm}$, (b) $25 \mathrm{~nm}$, (c) $30 \mathrm{~nm}$, (d) $50 \mathrm{~nm}$. The bar is $100 \mathrm{~nm}$.

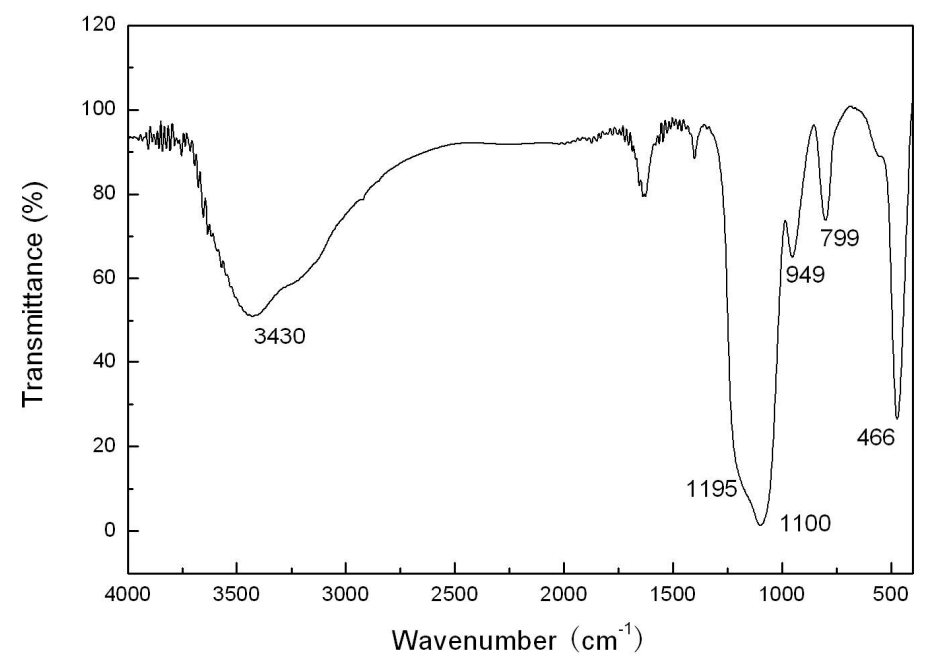

Figure S8. FTIR spectrum of the formed MWCNT/ZnS/SiO 2 heterostructures. 